\title{
SÍNDROME DE INSENSIBILIDADE COMPLETA AO ANDROGÊNIO: RELATO DE CASO DE UM HOSPITAL PEDIÁTRICO DE CURITIBA
}

\section{COMPLETE ANDROGEN INSENSITIVITY SYNDROME: CASE REPORT FROM A PEDIATRIC HOSPITAL IN CURITIBA}

Mylena Kormann¹, Soraya A. Rahman¹, Maiara T. Gehlen1, Marcela A. Moritz ${ }^{1}$, Laysla M. Mamus ${ }^{1}$, Geraldo Graça2

\section{RESUMO}

Resumo: A síndrome de insensibilidade periférica ao androgênio (CAIS), é a causa mais comum de pseudo hermafroditismo masculino. Nela ocorre insensibilidade periférica dos receptores à ação do androgênio, mas os níveis hormonais encontram-se dentro da normalidade até a puberdade. 0 resultado é o desenvolvimento de fenótipo feminino, apesar do genótipo masculino. Objetivo: Relatar um caso de CAIS de uma paciente acompanhada pelo serviço de endocrinologia de um hospital pediátrico de Curitiba. Método: Estudo retrospectivo. Discussão: Apresentamos o caso de uma paciente de um ano e três meses, com fenótipo feminino, diagnosticada com CAIS após realização de cirurgia por suspeita de hérnia inguinal. 0 diagnóstico foi firmado pela associação de fenótipo feminino, cariótipo 46XY e presença de testículos. Os testículos a princípio foram colocados dentro da cavidade abdominal. No início do acompanhamento, a paciente não apresentava sinais de puberdade. Foi realizado seguimento clínico-laboratorial com dosagens hormonais e manutenção dos testículos até o fim da puberdade. A paciente teve a adrenarca e início da puberdade aos 12 anos, com o aumento esperado das dosagens hormonais (FSH, LH e testosterona). Atualmente, espera-se o fim da puberdade para proceder à gonadectomia profilática, devido ao risco de neoplasia. Conclusão: $\mathrm{Na}$ CAIS, o hormônio masculino não é capaz de exercer seus efeitos biológicos na diferenciação da genitália externa, levando a um fenótipo feminino apesar do genótipo masculino. As gônadas devem ser removidas, devido ao risco neoplásico, eventualmente podendo aguardar a puberdade.

Descritores: Insensibilidade. Androgênios. Pseudo hermafroditismo. Testículos feminilizantes.

\section{ABSTRACT}

\begin{abstract}
Complete androgen insensitivity syndrome (CAIS) is the most common cause of male pseudohermaphroditism. There is complete insensitivity to the effects of androgens, despise normal hormonal levels. It results in a female phenotype and a male genotype. Objectives: to report a case of CAIS in a patient. Methods: retrospective study. Report: a female phenotype child aged 1 year and 3 months was diagnosed with CAIS after a surgery for a suspected inguinal hernia. The association of female phenotype, 46XY karyotype, and male gonads made the diagnosis. At first, the testicles were not removed. In the first consult, the patient had a M1P1 Tanner's stage and the expected clinical findings for the syndrome. Follow- up was done with serial hormonal measurements and clinical evaluations. The patient had her adrenarche at the age of 12 years, and concurrent elevation of hormonal serum levels. At the moment, she waits the end of her puberty to undergo prophylactic gonadectomy due to risk of neoplasm. Conclusion: CAIS is characterized by impairment in the effects of androgens, leading to a female phenotype and a male genotype. In time, the patient's gonads must be removed, as to prevent neoplasms.
\end{abstract}

Keywords: Insensitivity. Androgens. Pseudohermaphroditism. Feminizing testes.

\footnotetext{
1. Acadêmicas do curso de Medicina da Escola de Medicina da Pontifícia Universidade Católica do Paraná (PUC-PR), Curitiba, Paraná

2. Médico pediatra, docente do curso de Medicina da Escola de Medicina da Pontifícia Universidade Católica do Paraná (PUC-PR), Curitiba, Paraná
}

Contato do Autor / Mail to:

Mylena Kormann - mykormann@hotmail.com 


\section{INTRODUÇÃO}

A síndrome da insensibilidade completa ao androgênio (CAIS), descrita por Morris em 1953 na revista de ginecologia americana refere-se a indivíduos de fenótipo feminino, porém com genótipo e gônadas masculinos $^{1}{ }^{2}$. Ela apresenta prevalência de cerca de 1:10.000, sendo ainda mais rara em negros. Na síndrome, a síntese de testosterona é normal, porém há resistência dos tecidos à ação androgênica, o que causa a aparência feminina dos portadores ${ }^{2,3}$. Esta condição é causada por uma mutação na produção do gene receptor de androgênios ( AR; Xq 11 -q12), o receptor de estrogênio é normal e, portanto, ocorre desenvolvimento dos seios e do corpo feminino 1,4

A maior parte dos casos ocorre por herança recessiva ligada ao $X$, porém em $1 / 3$ dos casos não há relação familiar ${ }^{1}$. o diagnóstico pode ocorrer desde ao nascimento até após a puberdade. As gônadas costumam ser detectadas na cavidade abdominal ou na região lábioinguinal $^{2}$. Como em 15 a $25 \%$ dos casos ocorre transformação neoplásica, principalmente por gonadoblastomas benignos e disgerminomas malignos das gônadas na fase adulta, recomenda-se a gonadectomia profilática $^{1,5,6}$

É o objetivo deste artigo descrever um caso de síndrome da insensibilidade completa ao androgênio e, em seguida, realizar uma breve revisão de literatura.

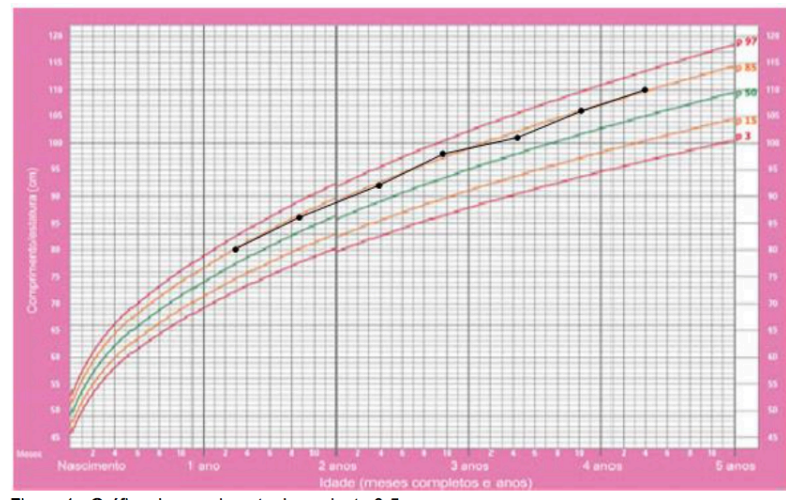

Figura 1 - Gráfico de crescimento da paciente 0-5 anos

\section{RELATO DE CASO}

Paciente L.M., fenótipo feminino, um ano e três meses, foi submetida em julho de 2004 a procedimento cirúrgico para correção de massa palpável em canal inguinal à direita, sugestiva de hérnia inguinal. Durante a cirurgia houve suspeita, pelas características da massa, de tratar-se de gônadas masculinas, sendo então optado por não a ressecar, mas somente realizar uma biópsia. 0 material foi enviado para análise histológica, apresentando laudo compatível com fragmentos de testículo.

Após resultado anatomopatológico as gônadas foram reinseridas na cavidade abdominal e foi aventada a hipótese de CAIS. Durante a investigação, foram solicitados ecografia abdominal, na qual não foram observadas estruturas genitais internas femininas (útero, trompas e ovários), e cariótipo, que demonstrou genótipo masculino (46XY).

Ao exame físico, a paciente apresentava genitália externa feminina, sem testículos palpáveis. A paciente encontrava-se em estágio M1P1 de Tanner, peso no percentil $75(12 \mathrm{~kg})$ e estatura entre os percentis 75 e 90, acima do canal familiar de crescimento.

Antecedentes gestacionais sem intercorrências, mãe G1P1, peso ao nascer de $3700 \mathrm{~g}$, estatura de $50 \mathrm{~cm}$, nascida por parto cirúrgico, a termo. Desenvolvimento neuropsicomotor com principais marcos dentro dos padrões de normalidade. Pais saudáveis e ausência de casos semelhantes na família.

Depois de firmado o diagnóstico de CAIS, foram efetuadas orientações gerais aos pais em relação à síndrome, explicado sobre o acompanhamento clinico e laboratorial com dosagens hormonais (testosterona, androstenediona, hormônio luteinizante [LH] e hormônio folículo-estimulante [FSH]), assim como o plano terapêutico de gonadectomia pós-puberal.

Apesar da dificuldade de aceitação por parte da família nos primeiros meses subsequentes ao diagnóstico, sendo necessário acompanhamento psicológico, a criança apresentou bom desenvolvimento psicossocial. A paciente foi acompanhada através de consultas periódicas, sendo mensurados em todas as consultas os parâmetros de desenvolvimento como peso e altura (Figuras 1 e 2), além de controle laboratorial (Gráfico 1).

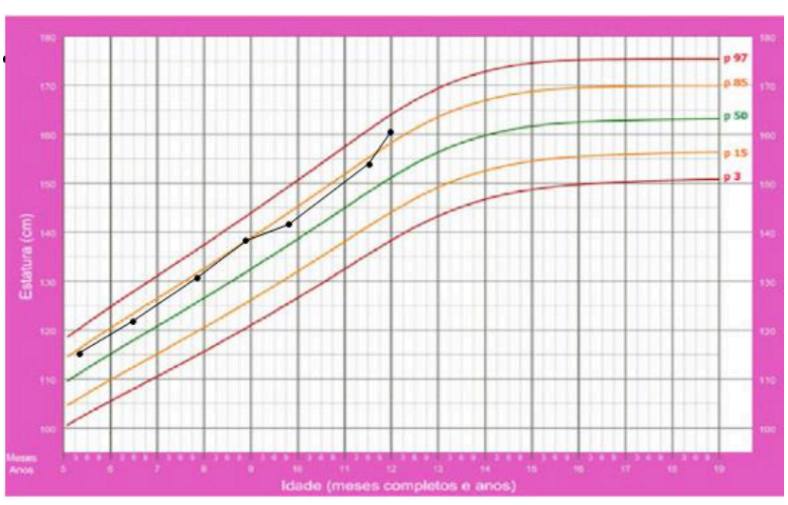

Figura 2 - Gráfico de crescimento da paciente 5-19 anos

Aos 12 anos e 2 meses a paciente apresentou odor axilar aumentado (adrenarca) e telarca grau 3 pela escala de Tanner, sem pubarca. Na ocasião, foi solicitada nova ecografia pélvica, que apresentou laudo coerente com a ecografia realizada ao diagnóstico.

Atualmente, L.M. segue em acompanhamento clínico, com plano de gonadectomia pós-puberal.

\section{DISCUSSÃO}

A síndrome de insensibilidade completa ao Androgênio (CAIS), também conhecida como síndrome dos testículos feminilizantes, é a causa mais comum de 
pseudo hermafroditismo masculino e a terceira causa de amenorréia primária ${ }^{2}$. Os hormônios androgênicos, além de definirem o fenótipo masculino são fundamentais para o desenvolvimento e manutenção dos caracteres sexuais secundários, iniciação e manutenção da espermatogênese. Os portadores de CAIS, apesar da produção normal de androgênios, são insensíveis a seus efeitos e, portanto, apresentam-se assim como a paciente do caso relatado, com fenótipo feminino e genótipo masculino $^{7,8}$.

\section{Gráfico 1 - Progressão das dosagens hormonais conforme a idade da paciente}

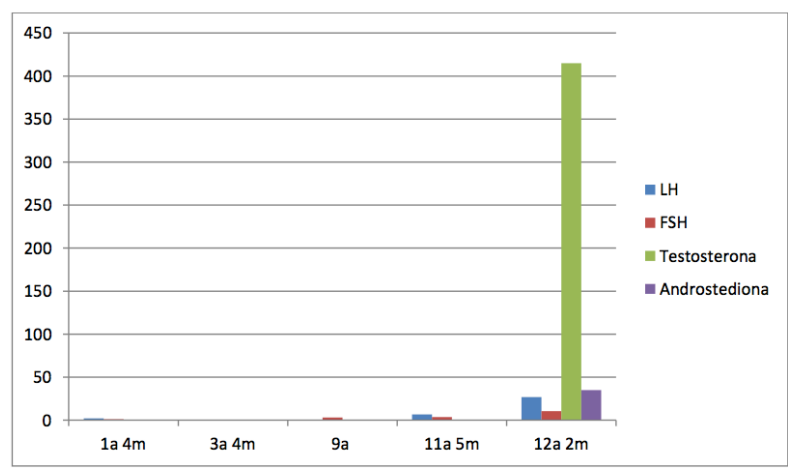

Portadores dessa síndrome apresentam genitália externa feminina, vagina ausente ou curta terminando em fundo cego, genitália interna sem as estruturas derivadas dos ductos de Wolff e de Müller, desenvolvimento de ginecomastia na puberdade e ausência de pelos pubianos ou axilares. Os testículos estão localizados no abdome ou canal inguinal e menos frequentemente nos grandes lábios $2,9,10$

No primeiro ano de vida, ao exame físico, a paciente apresentava genitália externa feminina; não foram palpados testículos, as mamas foram classificas em M1 e os pelos em P1 pela escala de Tanner. Aos 12 anos ocorreu adrenarca e desenvolvimento de mamas em M3.

A carência de atividade biológica da testosterona e da diidrotestosterona não suprimem a alça de feedback negativo, levando a produção de FSH e LH pelo eixo hipotálamo-hipofisário. Este aumento na produção de FSH e LH causa a produção excessiva de androgênios, que são convertidos em parte em estrogênios nos tecidos gordurosos. O hiperestímulo testicular ainda leva a produção indireta de estrogênios na periferia. Como resultado da presença de estrogênios circulantes, há o desenvolvimento de caracteres sexuais secundários femininos 2,8 .

A paciente teve seguimento hormonal com dosagens seriadas de testosterona, androstenediona, LH e FSH. Todos estes apresentando aumento importante aos 12 anos e 2 meses (fase de puberdade).

O crescimento e desenvolvimento da paciente foram acompanhados e mostraram-se dentro do esperado para o canal familiar e idade, respectivamente. Em decorrência do risco de transformação neoplásica das gônadas, foi optado pelo seguimento anual e gonadectomia pós-puberal, associado a reposição de estrogênio. Cerca de $25 \%$ das gônadas masculinas mantidas em abdome tornam- se neoplasias, justifica o plano de gonadectomia profilática proposto $3,4,6,7$.

\section{CONCLUSÃO}

Em conclusão, na síndrome de insensibilidade completa ao androgênio, o hormônio masculino não exerce efeito sobre seu receptor periférico, sendo este defeito o cerne para a discrepância entre fenótipo e genótipo ${ }^{8,11}$.

Nos casos de CAIS, as gônadas devem ser removidas, devido ao risco neoplásico após a puberdade. Subsequente à gonadectomia inicia-se terapia de reposição hormonal estrogênica, visando à manutenção de características sexuais secundárias femininas ${ }^{2,10}$.

\section{REFERÊNCIAS}

1. Warne, GL. Síndrome da insensibilidade androgênica completa. 1997, p.1-27

2. De Queirós RCG. Insensibilidade androgênica completa e hérnia inguinal. Relato de 3 casos. UFSC.1999.

3. Freitas F, Souza C, Salazar C. Pseudo Hermafroditismo Masculino. Jornal da Sociedade Brasileira de Ginecologia Endócrina. 2001; 8 (3).

4. Cai, L. Androgen Insensitivity Syndrome. The International Encyclopedia of Human Sexuality, 2015, p.1-111.

5. Barba, D; Silva, CR; Silva, JH; Barros, VS; Oliveira, JN. Sindrome de Morris: Relato de caso de irmãs com Síndrome de insensibilidade aos andrógenos.

6. Semple ,RK; Savage, DB; Cochran, EK; Gorden, P; O'Rahilly, S; Genetic syndromes of severe Insuline resistance. Endocr Rev, vol 32, 2011, p.498-514

7. Correa RV, Wey JC, Billerbeck AE, Melo KF, Mendonça BB, Wey MV, Arnbold IJ. Insensibilidade Completa aos Andrógenos em pacientes brasileiras causada pela mutação P766A no gene do receptor androgênico. Arq Bras Endocrinol Metab. 2005; 49 (1): 95-102.

8. Farah AL, Gauza JE, Junior LSN, Farias CC, Junior HF, Lampa VM. Síndorme de Sensibilidade Completa aos Androgênios: Relato de um caso tratado por videolaparoscopia. Associação Catarinense de Medicina. 2006; 35: 74-77.

9. López JÁ, Sánchez JÁ, Delgado GA, Martín LE. Morris Syndrome. Revista Cubana de Obstetricia y Ginecología. 2012; 38 (3): 415-423.

10. Avezum, Álvaro et AL. Diagnóstico e tratamento. 1a edição. Barueri: Manole; 2007. 1808p. (Volume 3)

11. Osório MR, Borges R. Wanyce M. Genética Humana. 3a edição. Porto Alegre: Artmed; 2003. 765p 